\title{
Varmint Countermeasure System
}

\author{
Ayaka Ito $^{\mathrm{a},}$, Seiichi Serikawa ${ }^{\mathrm{b}}$, Yuhki Kitazono ${ }^{\mathrm{a},{ }^{*}}$ \\ ${ }^{a}$ National Institute of Technology, Kitakyushu College, 5-20-1 Shii, Kokuraminami-ku, Kitakyushu-city Fukuoka \\ 802-0985, Japan \\ ${ }^{\mathrm{b}}$ Kyushu Institute of Technology, 1-1, Sensui-cho, Tobata, Kitakyushu, Fukuoka, 804-8550 Japan \\ *Corresponding Author: kitazono@kct.ac.jp
}

\begin{abstract}
This is the system to repel birds which gather on the veranda and a garbage dump. We often see sparrows and crows at a town, but they soil on veranda by droppings and scavenge on the garbage in the garbage dump.

In this study, we have developed the system that repel birds which gather on the veranda or a garbage dump with water gun that has been equipped with the device, the system detects the birds from camera image by image processing. Since repel by jetting water, it does not injure birds. Also, the water gun rotates vertically and horizontally by the motors. So as long as it is within a predetermined in such veranda, it is possible to repel birds if birds exist anywhere.
\end{abstract}

Keywords: Image processing, background subtraction method, the servo motor

\section{Introduction}

In the public garbage dump, we often see the birds such as crows are scavenging on garbage. Crow is very clever, so even the garbage is covered with net, they remove it and scavenge the garbage if we cover with the net many times. In addition, because the crows are fierce, they have gathered a lot, it is not easy to walk nearby or to repel. Also, in the home of veranda, pigeons and sparrows invaded soil by droppings, make a nest, and lay eggs. These acts aren't very good hygienically ${ }^{(1)-(2)}$.

Removal of pigeon nest is very troublesome, so professional exist. The pigeon has what is called a "homing instinct", so they have very strong attachment to the place where chicks live and the place where they made a nest. Moreover, if they recognize the location safety, try to make a nest persistently even if human get rid of it. It is very hard to get rid of the nest and repel pigeons perfectly.

The following is a well-known way to get rid of the varmint.

(a) Repel with the sound and light

Such as veranda, it is very well-known way to hang glittering CD disc, and menace with loud sound and ultrasound. However, just keep hanging glittery things just get used birds, so there is a possibility that the effect weakens. In addition, in the way to repel with loud sound, there is also the risk of developing the noise problem cases, such as condominiums.

(b) Repel with a magnetic

Birds felt the geomagnetism in the direction to fly, it is said to be flying. Therefore, if the geomagnetism is disturbed by strong magnetism, birds lose the sense of direction and take evasive action. However, the birds living in the city (such as sparrows and crows) get used to magnetism, and in some cases the effect is thin.

(c) Repel with a smell

Because the smell exist that varmint doesn't like, scatter with the water or the spray of that smell on such as veranda.

(d) Hang a doll that imitates a crow

Crow feel fear for the carcass of fellow, so if a doll which imitates a carcass of crow is hang, crows don't approach there because they think the doll to the carcass of fellow.

However, examples mentioned in the above may be effective at first, but there is anxiety that birds gradually acclimate. If birds acclimated, they gather in the same place or make a nest in the same way. In this study, we focused on the way that birds cannot acclimate. In order to materialize that, we adopted the way to hit water to pinpoint the bird for move the device every time. The water that 
birds dislike (Pigeon Guard, TOYAKU CO.,LTD) is used. Because birds dislike watered, the effect can be expected. In this way, birds don't acclimate. Moreover, the system detects birds exactly by image processing, so doesn't shoot water to human by mistake. Also other varmint countermeasure system, in order to inject water, requires faucet leading to the hose. Therefore, it cannot be used in apartment veranda and so on. On the other hand, in the system of the study, since moving the device after putting water in water gun in advance, it can be used in place there is no water. Since we have devised "the automatic recognition system day and night the crow with a camera ${ }^{(5),}$, This equipment can distinguish birds from human and recognize the position of the bird in the system. In this study, we have developed the system that repel birds to repel by inject water to the position of birds.

\section{Varmint Countermeasure System}

\subsection{Configuration}

The configuration of the system is as follows. Appearance of the unit is shown in Fig. 1.

(1) Recognize the position of the birds. (We have already done it in past study.)

(2) Turn the water gun on birds.

(3) Shoot the water.

\subsection{Recognition of the position of the bird}

The Varmint Countermeasure System recognizes the birds using an infrared camera. In this system, we used the detecting birds process that we have developed in the study: "Proposal of System for Automatic Recognition of Crows at Day and Night Using Camera"(5). Moving birds were detected by using a background subtraction method. A background subtraction is a method of detecting a moving object in the image from fixed camera. An infrared camera sets up, and acquires the image when there is no motion. If a moving object such as a bird enters there, the images are acquired that different from the images acquired before. It is possible to detect the moving object by comparing the image acquired before with newly acquired image. In previous study, it surrounds the extracted object in the circumscribed rectangle, and then using the area and the aspect ratio of the part, it determines the moving object whether the crows. It can detect both by day and by night the number and location of the bird and human. Fig. 2 is the previous image to detect the moving object, and Fig. 3 is

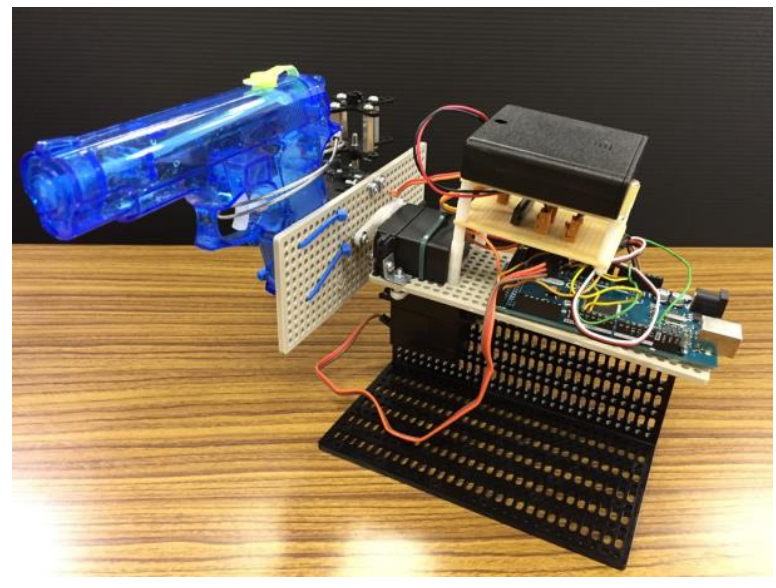

Fig. 1. Unit to repel birds.

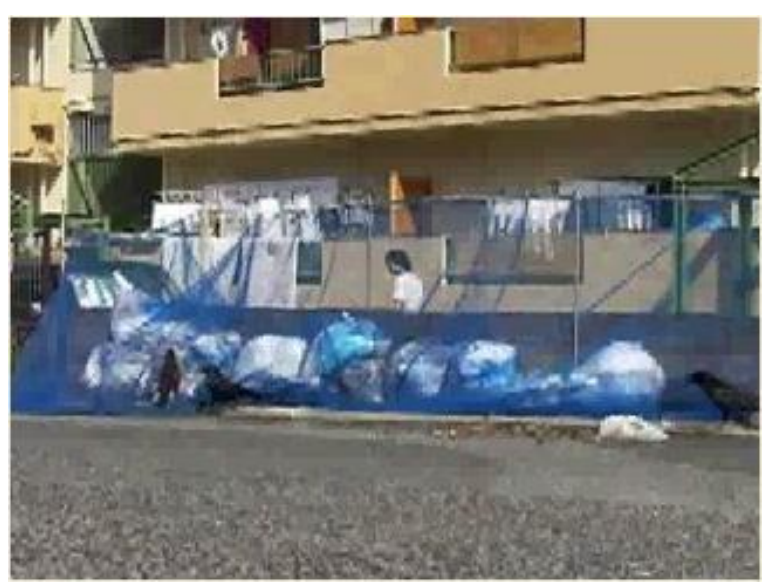

Fig. 2. Before the bird detection ${ }^{(5)}$.

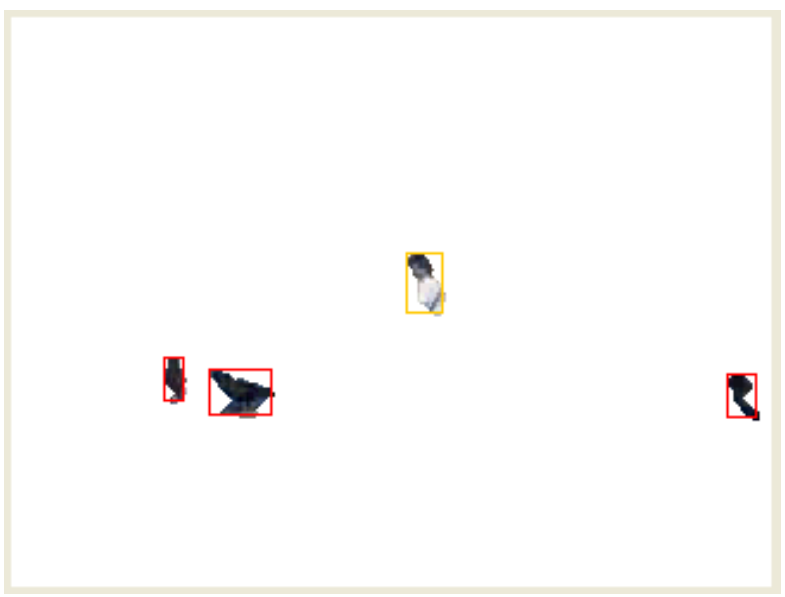

Fig. 3. After the bird detection ${ }^{(5)}$.

the image after detecting the moving object.

\subsection{Angle adjustment of the water gun}

Next, in order to fire the water at aimed position, it adjusts the angle of the water gun. 


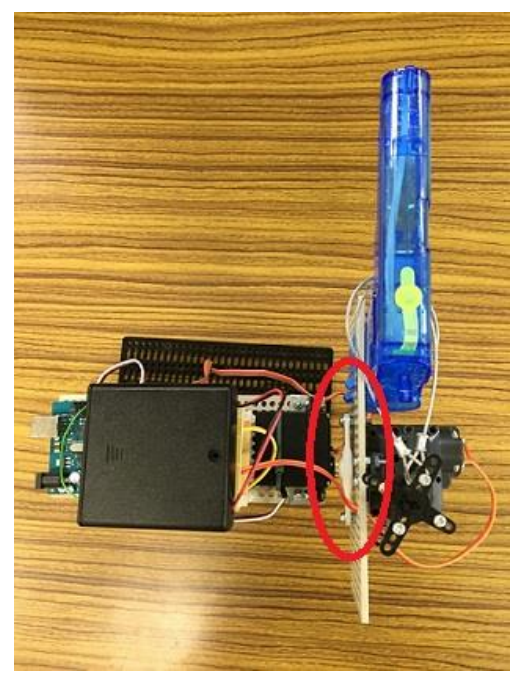

Fig. 4. Vertical angle.

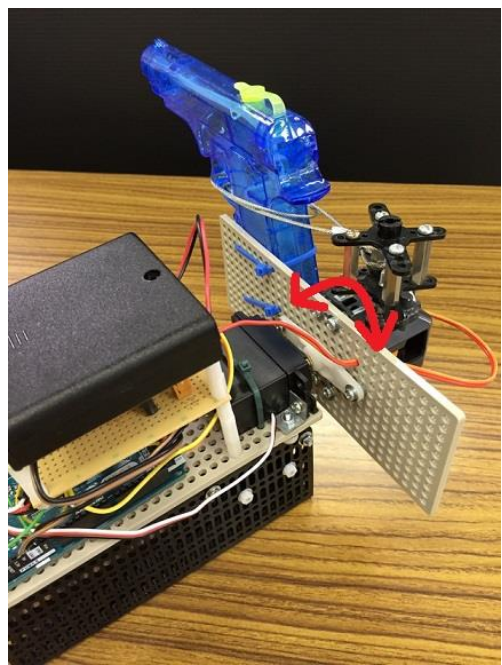

Fig. 5. The adjustment of the vertical angle.

As shown in Fig. 4 and Fig. 6, it has set up servo motors in the parts that written red circles. Vertical angle moves as shown in Fig. 5 and horizontal angle moves as shown in Fig. 7. After determining the position by image processing, servo motor rotates toward its position, and it adjusts the horizontal angle and vertical angle of the water gun. Therefore, it possible to turn the water gun wherever birds are.

\subsection{Fire the water}

After adjusting the angle of the water gun, shoot the water by pulling the trigger. It should put the water to water gun in advance. As shown in Fig.8, water gun is the weight that was placed in the water, so it is fixed to the universal plate with cable ties so that it doesn't shake when the trigger was pulled. The trigger is wound on the wire.
Table 1. Equipment.

\begin{tabular}{|c|c|c|}
\hline Equipment & $\begin{array}{c}\text { Manufacture } \\
\text { name }\end{array}$ & Model number \\
\hline Water gun & NARICHIKAYA & - \\
\hline $\begin{array}{c}\text { 4-Speed Worm } \\
\text { Gearbox H.E. } \\
\text { (Gear ratio 84:1) }\end{array}$ & TAMIYA & 72008 \\
\hline Servo Motor & GMServo & S03T 2BBMG \\
\cline { 3 - 3 } & & S19 CLMG \\
\hline
\end{tabular}

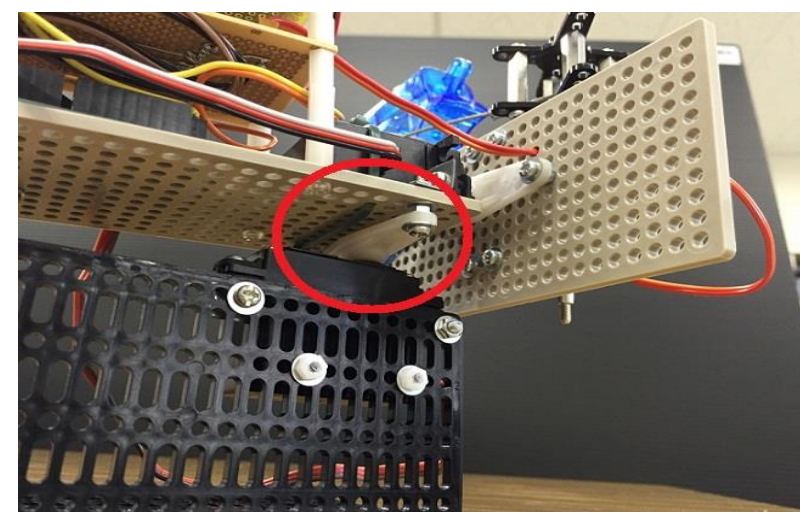

Fig. 6. Horizontal angle.

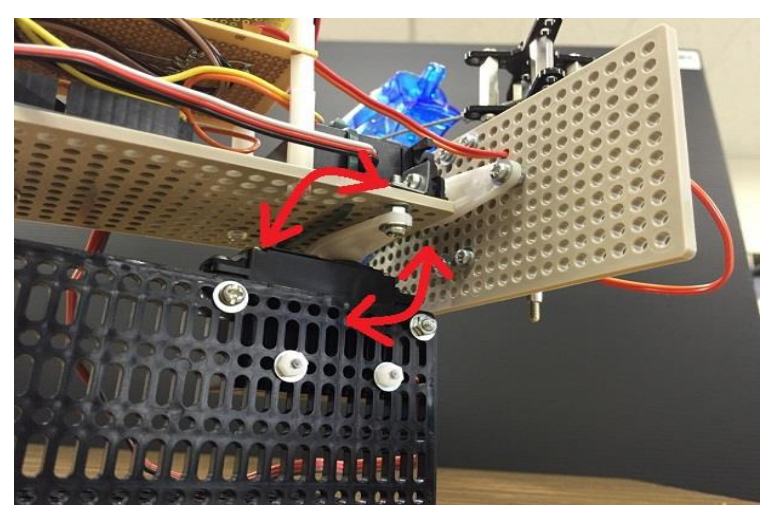

Fig. 7. The adjustment of the horizontal angle.

Previous wire is attached to the motor. The gear ratio of motor is $84: 1$, and we have wound the wire to double for the trigger. When the motor is rotated, the wire is wound around the motor, and the trigger is pulled as shown in Fig. 8 and Fig. 9. In addition, the motor is attached to four bars as shown. By doing so, the portion for winding the wire approaches the circle of large diameter, so it can be wound smoothly with a small rotational speed. And it is not possible to determine the three-dimensional position in the image processing, so shakes the vertical angle up and down while fire water. By this movement, this device can hit water the object in front and the object of back. For vertical angle, it will be verified in Section 3.4. 
Table 2. Flying distance of the water.

\begin{tabular}{|c|c|}
\hline Times & Flying distance of the water $[\mathrm{cm}]$ \\
\hline 1 & 214 \\
\hline 2 & 226 \\
\hline 3 & 230 \\
\hline 4 & 198 \\
\hline 5 & 211 \\
\hline & Average: 215.8 \\
\hline
\end{tabular}

Table 3. Flying the water.

\begin{tabular}{|c|c|}
\hline $\begin{array}{c}\text { Horizontal angle / } \\
\text { Vertical angle }\end{array}$ & Distance $[\mathrm{cm}]$ \\
\hline$-90 /+45$ & 273 \\
\hline$-45 /+45$ & 279 \\
\hline $0 /+45$ & 278 \\
\hline$+45 /+45$ & 280 \\
\hline$+90 /+45$ & 276 \\
\hline
\end{tabular}

\section{Experiment}

In this study, we performed the following experiments. Also the use equipment is shown in Table 1.

\subsection{Speed according to the rotation of the servo motor}

The servomotor used this time moves in the range of 0 degrees to 180 degrees as shown in Fig.10 and Fig.11. In the produced device, it has set the initial angle both horizontal and vertical angle to 0 degrees. In this experiment, we were measuring the time to reach the point from initial angle to -90 degrees, from initial angle to +90 degrees.

As a result, both horizontal angle and vertical angle, the time has arrived at the point of each of -90degrees and +90 degrees took approximately 0.5 seconds.

\subsection{The length of the water gun of injection}

When the device wound the trigger automatically by turning the motor, the equipment was measured how many meters injection the water. It's connecting the DC motor to the power supply of $5 \mathrm{~V}$. This experiment was conducted five times from the same location. Injection angle (vertical angle) is 90 degrees, which is an initial angle. Also, the equipment was placed on the chair height $39.5 \mathrm{~cm}$, and the height of the floor-to-muzzle it was $57 \mathrm{~cm}$. The results are

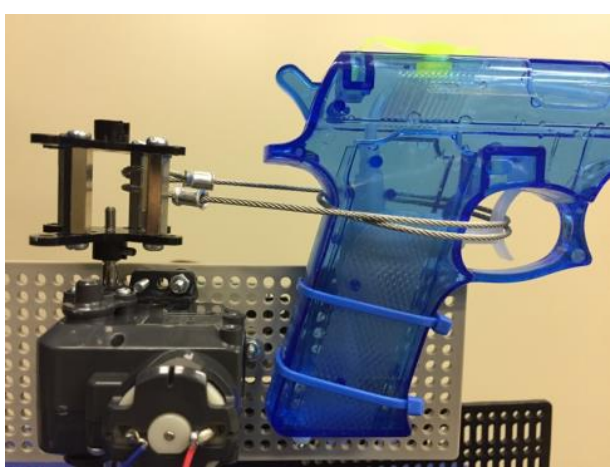

Fig. 8. Before pull the trigger.

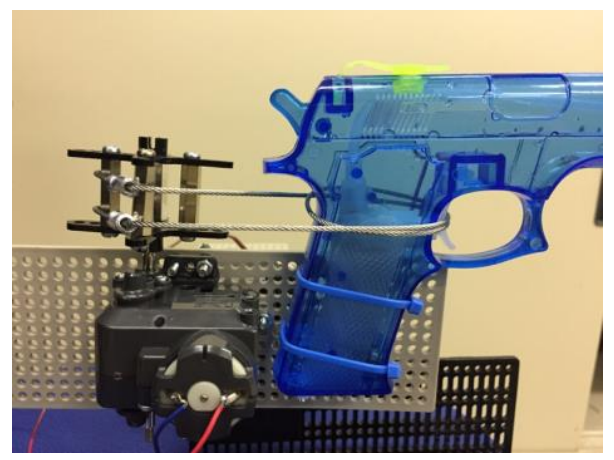

Fig. 9. After pull the trigger.

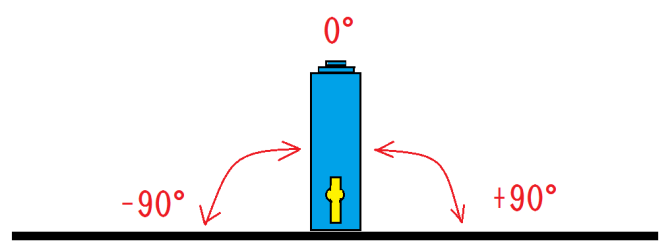

Fig. 10. Horizontal angle.

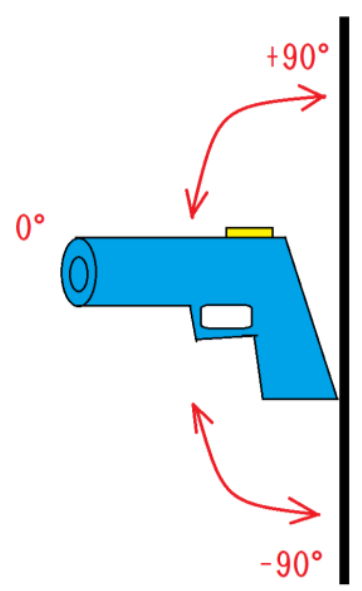

Fig. 11. Vertical angle.

shown in Table 2.

\subsection{Injection range of water}

We ware measuring the injection range of water. The 
Table 4. The case of objects came higher place.

\begin{tabular}{|c|c|c|}
\hline $\begin{array}{c}\text { The distance from } \\
\text { the water gun[cm] }\end{array}$ & $\begin{array}{c}\text { Height above } \\
\text { the ground[cm] }\end{array}$ & $\begin{array}{c}\text { Vertical } \\
\text { angle[degrees] }\end{array}$ \\
\hline Position1:61 & 55 & +33 \\
\hline Position2:106 & 46 & +26 \\
\hline Position3:133 & 40 & +17 \\
\hline Position4:157 & 34 & +13 \\
\hline Position5:212 & 21 & +11 \\
\hline
\end{tabular}

vertical angle of the water gun is fixed to +45 degrees, and the horizontal angle manipulated from -90 degrees to +90 degrees. Height from the floor-to-muzzle is same as the experiment 3.2. The results are shown in Table.3.

\subsection{Determination of the three-dimensional alignment}

In fact there are points where depth is different though $\mathrm{x}$-axis and $\mathrm{y}$-axis are same position in the image. So, in Section 3.4, we experiment by changing the vertical angle of the water gun whether water hit the moving bodies that vary the depth although the same position on the screen.

In this Section, we experimented in the case that the moving bodies came higher place than water gun and in the case that the moving bodies came lower place than water gun. And in this experiment, we put the object of vertical $9 \mathrm{~cm}$ and horizontal $20 \mathrm{~cm}$, and hit water with it. Also, we have set up a web camera from the ground to the position of $72 \mathrm{~cm}$.

(a) The case that the object came higher place than the water gun

We put the water gun on the ground. It is $15 \mathrm{~cm}$ from the ground to the muzzle of the water gun. We found out the distance in the depth of 5 points overlapping $\mathrm{X}$-axis and $y$-axis on the screen, and measured the depth. Also, we have established the water gun, and measured the angle at which the water hits the body. The results are shown in Table 4.

As shown in Table 4, from position 1 to position 5, by operating the vertical angle of the water gun about 25 degrees, water hit the object at any distance.

(b) The case that the object came lower place than the water gun

We put the water gun at a high position. It is $87 \mathrm{~cm}$ from the ground to the muzzle of the water gun. We repeated the experiment of Section (a). The results are shown in Table 5.

As shown in Table 5, from position 1 to position 5, by operating the vertical angle of the water gun about 20 degrees, water hit the object at any distance.
Table 5. The case of objects came lower place.

\begin{tabular}{|c|c|c|}
\hline $\begin{array}{c}\text { The distance from } \\
\text { the water gun[cm] }\end{array}$ & $\begin{array}{c}\text { Height above } \\
\text { the ground[cm] }\end{array}$ & $\begin{array}{c}\text { Vertical } \\
\text { angle[degrees] }\end{array}$ \\
\hline Position1:61 & 55 & -15 \\
\hline Position2:106 & 46 & -7 \\
\hline Position3:133 & 40 & -4 \\
\hline Position4:157 & 34 & -1 \\
\hline Position5:212 & 21 & +4 \\
\hline
\end{tabular}

\section{Conclusions}

In this study, we devised a system to repel birds which gathered on the veranda and garbage dump. From experiments, we were able to confirm that the device can adjust the angle of the water gun toward any direction and pull the trigger on automatic. Using this device, effect for pigeons and crows, (which was difficult to repel) is expected. Owing to its property that it repels birds by shooting water, it can repel them without causing injury against them.

For future assignments, we would like to extend the range of water gun, and improve the hit accuracy of water gun. By improving there, we would like to build a system to repel the birds more reliably.

\section{References}

(1) Takashi Kanda, Masato Akiyama, Fumihiko Kawamori, Masaaki Sugieda and Sousuke Akahane: "Epidemiological survey of Chlamydia psittaci of pigeons in Shizuoka prefecture", The Journal of The Japanese Society of Pestology, Vol. 7, No. 1, pp. 22-24, 1992

(2) Masahumi Fukuyama, Youichi Kakuno, Motonobu Hara : "Studies on Vero toxin-producing Escherichia coli (VTEC) Infection : Isolation and serotypes of Vero toxin-producing Escherichia coli (VTEC) from pigeons and crows", Journal of Azabu University, Vol. 5,6, pp. 194-198, 2002

(3) Yuki Kitamoto, Sinji Umesaki, Masahiro Sakibe, Yuhki Kitazono, Shota Nakashima, Shiyuan Yang, Seiichi Serikawa: "Proposal of System for Automatic Recognition of Crows at Day and Night Using Camera", Record of 2009 Joint Conference of Electrical and Electronics Engineers in Kyushu, No.01-2A-07, 2009 